OPEN ACCESS

Edited by:

Fu-Sheng Tsai,

Cheng Shiu University, Taiwan

Reviewed by:

Cheng Hung Tsai,

Cheng Shiu University, Taiwan

Shih-Chih Chen,

National Kaohsiung First University of

Science and Technology, Taiwan

Hao Jiao,

Beijing Normal University, China

*Correspondence:

Tachia Chin

tachia1231@yahoo.com.sg

Specialty section:

This article was submitted to

Organizational Psychology,

a section of the journal

Frontiers in Psychology

Received: 26 March 2019 Accepted: 28 June 2019

Published: 17 July 2019

Citation:

Li Z, Dai L, Chin T and Rafiq M (2019) Understanding the Role of Psychological Capital in Humorous Leadership-Employee Creativity Relations.

Front. Psychol. 10:1636.

doi: 10.3389/fpsyg.2019.01636

\section{Understanding the Role of Psychological Capital in Humorous Leadership-Employee Creativity Relations}

\author{
Zhengwei Li', Lihua Dai, ${ }^{1,2}$, Tachia Chin ${ }^{1 \star}$ and Muhammad Rafiq ${ }^{1}$ \\ 'School of Management, Zhejiang University of Technology, Hangzhou, China, ${ }^{2}$ School of Economics and Management, \\ Hangzhou Normal University, Hangzhou, China
}

This paper aims to examine how humorous leadership enhances employee workplace creativity from a novel angle of employee psychological capital (EPC). This study also explores the moderating roles of supervisor-subordinate dyadic tenure and work autonomy in the proposed model. Data from a sample of 355 supervisor-subordinate dyads working in an information technology enterprise in the People's Republic of China was used to test the assumed moderated mediation model. The results indicate the positive relationship between humorous leadership and employee workplace creativity, which is partially mediated by EPC. Moreover, work autonomy significantly moderates the relationship between EPC and employee creativity. Humorous leadership has a significant effect on the extra role behavior of subordinates, leading to workplace creativity. The deliberate establishment of a humorous image by leaders may encourage subordinates to achieve creative goals. Combined with traditional management practices that emphasize the supportive behaviors of leaders, leaders can use humor to provide an open and friendly atmosphere for employees, thereby encouraging creativity in the workplace. Organizations should also place greater emphasis on employee work autonomy, giving employees enough flexibility on when and how they deal with their work; this could enhance the positive impact of other factors on employee workplace creativity. These findings carry implications for research on humorous leadership, EPC, and creativity.

\footnotetext{
Keywords: humorous leader, psychological capital, supervisor-subordinate dyadic tenure, work autonomy, employee creativity
}

\section{INTRODUCTION}

A large body of literature has highlighted the significant role employee creativity plays in enhancing organizational innovation, effectiveness, survival, and competitiveness (Gong et al., 2009; Ghosh, 2015; Iqbal et al., 2015; Zubair and Kamal, 2015). Many scholars have explored how to drive employee creativity better. According to these studies, leadership styles can motivate employees (Iqbal et al., 2015; Goswami et al., 2016; Musinguzi et al., 2018) and enhance employee psychological capital (EPC), that is, the positive psychological state of their employees (i.e., hope, resilience, optimism, and efficacy) (Luthans et al., 2007), seems to be critically 
important in harnessing an employee's creative potential. Moreover, the mediating role of EPC in the relationship between leadership style and employee creativity has been widely discussed. For instance, Rego et al. (2012) found that EPC mediates the association between authentic leadership and employee creativity. Gupta and Singh (2014) and Gong et al. (2009) highlighted the mediating impact of EPC on the relationship between transformational leadership and employee creativity. Zhang and Bartol (2010) demonstrated the intervening effect of employee psychological state on the relationship between empowering leadership and employee creativity. Noticeably missing from the literature is an examination of "humorous leadership" and how it relates to EPC.

A leader's sense of humor might facilitate followers to think "outside of the box" and achieve greater creativity (Cooper, 2008). We argue that a leader's sense of humor may be of particular significance in motivating employee creativity in China. Because Chinese culture values high power, respecting for those in power is a prominent cultural characteristic among Chinese people (Nonaka and Zhu, 2012; Chin and Liu, 2015). As such, employees consider Chinese leaders to be unchallengeable authorities; leaders are perceived to take their work seriously and maintain a certain distance from their subordinates (Chan, 2014; Chin and Liu, 2015; Du et al., 2019). Scholars claim that humorous leadership may activate subordinates' creativity (Lang and Lee, 2010; Wood et al., 2011; Pundt, 2015; Yam et al., 2018), as humor allows for the playful combination of ideas that appear incongruent at first glance; through this, innovation emerges. Nevertheless, limited research has addressed the importance of humorous leadership in China, despite the wide recognition of its influence on employee innovation performance in western countries (e.g., Avolio et al., 1999; Vecchio et al., 2009; Robert and Wilbanks, 2012). To fill the gaps mentioned above, the current study aims to explore the relationships among humorous leadership, EPC, and employee creativity.

Although humorous leadership appears to be a popular kind of leadership, is it always helpful? We argue that humor is not a panacea. That is to say, although a leader's sense of humor may help to increase positive effect among subordinates, it may also increase the deviance of the subordinates. Because it is easier to communicate with a humorous leader, employees are more likely to break the company rules, and this will inevitably lead to confusion. Furthermore, in her qualitative study, Holmes (2007) reported that humorous comments during team meetings kept the idea generation process going, although humorously presented ideas were often unrelated to the actual solution. Evidence indicates that humorous leader often appears to be ineffective and unprincipled; this leaves a bad impression on employees who see their leader as a role model. The impact of humorous leadership on employee creativity is not created out of thin air; it is affected by some contingency factors. Therefore, the main purpose of this study was to build and test a theory that addresses the connection between humorous leadership and workplace creativity, including several important intervening variables.

In building a model linking humorous leadership and employee creativity, we further drew on Resource Conservation
Theory (Hobfoll, 1989) and Emotional Event Theory (Weiss and Cropanzano, 1996) to posit a mediating mechanism that can potentially explain the link between humorous leadership and employee creativity; specifically, EPC. EPC, defined as "an individual's positive psychological state of development," is characterized by: “(1) having confidence and self-efficacy to take on and put in the necessary effort to succeed at challenging tasks; (2) making a positive attribution about succeeding now and in the future; (3) persevering toward goals and, when necessary, redirecting paths to goals in order to succeed; and (4) when beset by problems and adversity, sustaining and bouncing back and even beyond to attain success" (Luthans et al., 2007). Thus, we explored the extent to which humorous leadership works through EPC to ultimately influence employee creativity. Although "creativity" can be used to describe both an outcome and a process, in this study, we use the word in the outcome sense-that is, to denote the extent to which novel and useful ideas are produced.

Finally, we proposed and tested two potentially important moderators of the relationship between humorous leadership and employee creativity: work autonomy and supervisorsubordinate dyadic tenure. Work autonomy refers to the extent to which employees can make decisions about their own work, such as when they work, who they work with, and so on. Supervisor-subordinate dyadic tenure refers to the duration of time an employee has worked together with his direct leader.

Overall, our purpose was to build a theory by conceptually and empirically linking Resource Conservation Theory and Emotional Event Theory to provide a more comprehensive understanding of the humorous leadership phenomenon as it relates to employee creativity.

\section{THEORY AND HYPOTHESES}

In this section, we trace the development of our overall research model by first exploring the general nature of humor and humorous leadership as it relates to creativity. Next, we investigate how humorous leadership influences EPC, as delineated by Luthans et al. (2007), including consideration of a potential moderator: supervisor-subordinate dyadic tenure. We then examine the influence of EPC on employee creativity. As part of these arguments, we incorporate work autonomy as a moderating variable to help explain how leaders can affect the extent to which EPC influences employee creativity. The hypothesized model is depicted in Figure $\mathbf{1}$.

\section{The Nature of Humor}

The word "humor" comes from the Latin word "homorem," with the original meaning of "liquid" or "fluid." Broadly defined, a sense of humor refers to an individual trait-like tendency to use or display behaviors, attitudes, and abilities relating to amusement during social interactions (Martin, 2001; Al Obthani et al., 2013). Research on humor has gradually entered into the field of organizational behavior. Sense of humor is often 


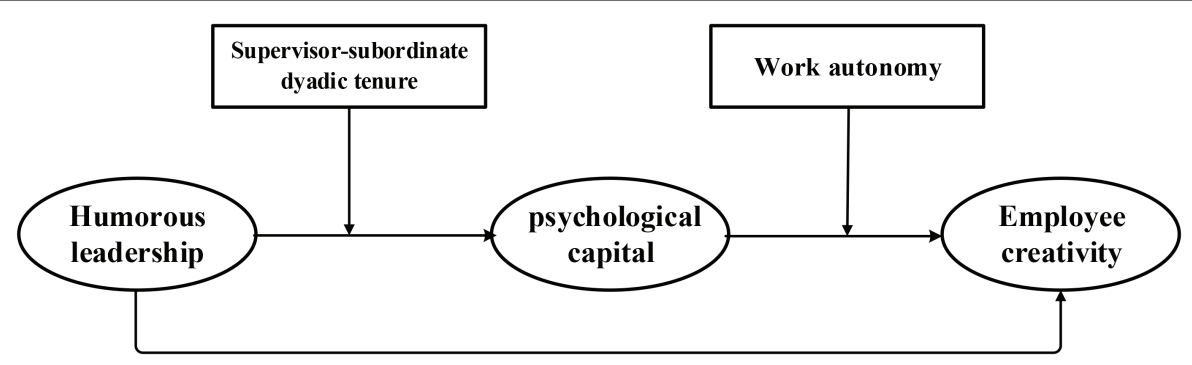

FIGURE 1 | Hypothesized model.

said to be a critical component of successful leadership (Sobral and Islam, 2015). Sense of humor in an organization may also be a means of relaying verbally expressed ingratiation behavior. Specifically, a humorous sender shares an event with others for the purpose of entertainment and pleasant, the recipient can feel this is intentional (Cooper, 2005).

The evolution of the concept of humor has mainly involved different views as to whether humor is a behavior or trait. The trait view holds that personal humor is a stable personality trait related to personal experiences and attitudes toward life. This view emphasizes that an individual's sense of humor is stable and consistent; it does not change greatly due to certain events or in special periods. It is mainly manifested in the behavioral tendency of individuals to actively capture, discover, and create humor in the workplace. However, the behavioral view argues that humor in the workplace is deliberately initiated to purposefully deliver interesting events to the recipient. The behavioral view emphasizes that the initiator intentionally creates and then sends a signal with humor, and then through the dissemination of the organizational media, the receiver analyzes and decodes. Finally, the receiver responds to the humor, such as with laughter, happiness, and other information dissemination processes.

At present, the behavioral view of humor is much more popular among scholars. Humor is regarded as a form and process of interpersonal communication in an organization. Humorous leadership refers to a leader, who is always consciously entertaining his subordinates by sharing interesting things (Robert et al., 2016). According to Martin et al. (2003), there exist four different styles of interpersonal humor: affiliative, self-enhancing, aggressive, and self-defeating humor. Since the 1980s, researchers have explored the impact of workplace humor on work efficiency. With consideration for the various dimensions of humor, many scholars have studied the relationship between humorous leadership and employee performance, mental health, work satisfaction, and so on (e.g., Avolio et al., 1999; Vecchio et al., 2009; Kim et al., 2016).

Research on leadership style is a hot topic in the study of organizational behavior. As an important type of leadership style, humorous leadership has attracted the attention of an increasing number of scholars. Empirical research has demonstrated that humor is closely related to organizational innovation, socialization, employee relationships, job satisfaction, work engagement, team cohesion, and so on (Bizi et al., 1988; Wood et al., 2011; Yam et al., 2018). Successful humor in an organizational setting can add the quantity and quality of effective communication within the team, alleviate boredom and frustration at work as well as improve the relationship between leader and employees, thus improving overall work efficiency.

Adriaenssens et al. (2015) investigated the relationships between various leadership styles and employee performance. The results showed that positive leadership styles, such as transformational leadership and contingent leadership, were positively related to humor. On the contrary, laissez-faire leadership was negatively related with humor. For positive leaders, the use of humor can make them look more confident and glamorous, allowing them to send positive signals to employees, so as to enhance team cohesion and create good organizational culture; thus, improving organizational innovation and team performance. For the sake of distinction, humor in this article only considers the positive aspects, including affiliative humor and self-enhancing humor; this paper does not take two negative kinds of humor (aggressive and self-defeating humor) into consideration.

\section{Humorous Leadership and Employee Creativity}

In general, creativity in the workplace is defined as the production of novel and useful ideas or solutions (Amabile, 1988; Shalley, 1991; Oldham and Cummings, 1996). According to this definition, both novelty and usefulness are necessary elements for an idea or product to be judged as creative (Zhou and George, 2003). In the context of creativity at work, an idea or product which only displays novelty or usefulness is not enough; a novel idea that has no potential value cannot be regarded as creative, nor can a useful product that is not significantly different from already available ones (Chang et al., 2015).

A survey of 329 Fortune 500 CEOs performed by Fortune magazine found that $97 \%$ of CEOs agree with the importance of humor in business; these findings call for CEOs to cultivate a greater sense of humor (Chen and Chen, 2011). So, how do humorous leaders influence employee innovation behavior? According to Benign Violation Theory (BVT; McGraw and Warren, 2010), it is necessary and beneficial to break some benign rules. Briefly, BVT suggests that the display of humor often necessitates a benign norm violation. Leaders' humorous behavior conveys to other members of the organization that breaking some existing rules is acceptable; thus, subordinates 
are more likely to increase workplace violations (Robinson and Bennett, 1995). In their eyes, violations are not "unforgivable," but safe to try. This kind of workplace violation allows employees continually explore new ideas without sacrificing the original production model; thus, increasing the possibility of innovation.

Evidence indicates that the atmosphere in the workplace plays an important intermediary role between human resource practice and organizational performance (Delaney and Huselid, 1996; Tsai et al., 2015). If employees feel their company attaches great importance to innovation, this will give them the belief that conducting innovative actions is encouraged; even if their innovation fails, they will not be punished, the subjective efforts of the employees will be stimulated and they will try innovative methods actively (Hommel et al., 2011). Conversely, if employees believe that the organization does not value innovation as they say, or that they will suffer big losses if they fail, then employees will be unlikely to try innovative and new processes or methods (Wang and Wang, 2018). Humorous leadership plays an important role in the creation of an organizational innovation atmosphere; in such an atmosphere, subordinates feel free to develop, communicate, and implement their ideas without any fear of negative consequences (Carmeli et al., 2010). Humorous leaders may make funny comments about upcoming mistakes, and subordinates face idea implementation with a more lighthearted and playful approach.

Further, humor is one kind of creativity itself; that is, humorous leadership gives way to creativity and idea generation as part of innovative behavior. According to BVT, incongruity is a cognitive element of humor (Yam et al., 2018). This means the first condition of humor is that at least two situational features are cognitively incompatible. Situations that violate expectations, but are simultaneously perceived as being normal overall, are typically perceived as humorous (Veatch, 1998). Thus, humorous leaders are models of person with creativity. Emotional Event Theory argues that the mental state of a leader can be perceived by the employees as an environmental impact, which in turn affects the attitudes and behaviors of the employees (Scott and Bruce, 1994; Weiss and Cropanzano, 1996). Humorous leader will positively influence subordinates, who see him as a role model, and thus, subordinates will introduce new process and ideas so as to find a common language with their leader (Lebedeva et al., 2018). Hence, humorous leadership has a positive effect on employee creativity:

H1: Humorous leadership is positively related to employee workplace creativity.

\section{Humorous Leadership, Employee Psychological Capital, and Employee Creativity}

Studies have shown that individual cognitive factors have a significant impact on employee innovation behavior (Tierney and Farmer, 2011). The influence of leadership on employee behavior is often not direct, but is generated by the internal psychology and cognition of employees (Shin and Zhou, 2003; Cho and Dansereau, 2010; Walumbwa et al., 2010). EPC, defined as "an individual's positive psychological state of development" includes four aspects: confidence (self-efficacy), optimism, hope, and resilience (Luthans et al., 2007). Although the study of EPC has mostly focused on its structural dimensions and its connotation level, we still have reason to believe that there is a close relationship between humorous leadership and employee EPC (Gupta and Singh, 2014; Wang et al., 2018).

The innovation process is full of complexity and uncertainty; employees need to have strong confidence and self-efficacy (Tierney et al., 1999; Silla and Gamero, 2018; Rafiq et al., 2019). Humorous leader garners trust and confidence from their subordinates through funny words and deeds. By providing cognitive, emotional, and ethical assistance to their employees, humorous leader enables them to develop their own abilities and promote their self-confidence. Through observing exemplary behaviors in a respectful manner, employees may develop greater confidence in their abilities to pursue goals (Rego et al., 2012). Individuals with higher self-efficacy are more likely to take risks and engage in challenging tasks, and are therefore more likely to use creative methods to solve problems (Gong et al., 2009). Participative goal setting enhances an individual's willingness and ability to design hope pathways. Breaking down difficult goals into smaller and more manageable milestones can also enhance hope in employees (Gupta et al., 2011). Humorous leaders usually have a good relationship with their subordinates, and tend to set work goals together with their subordinates. Further, humorous leaders increase their subordinates' level of optimism by creating a supportive work environment.

By providing positive feedback to their subordinates and expressing confidence in their abilities, humorous leader can motivate their employees to look on the bright side of things, redirect his employees away from the negatives and focus on the positives and available opportunities (Gupta et al., 2011). Through some fixed-themed training, humorous leader can demonstrate and teach realistic optimism to employees, and through this process, innovative behaviors among subordinates are promoted. Positive feedback and encouragement in the work from the leader can help enhance employees' resilience (Luthans et al., 2007). Resilience can also be enhanced by altering the perceived level of risk and generally fostering selfenhancement and development (Avey et al., 2009). In the face of pressure or adversity, humorous leader can help subordinates to respond positively. Therefore, when the subordinates face difficulties, they will not only persist, but ultimately succeed; this will help to improve the level of resilience in subordinates (Avolio and Walumbwa, 2006).

The innovation process is so difficult and uncertain that it requires employees to have an unwavering internal drive to transcend current challenges and setbacks in order to adapt to the changing environment. Resilient employees can be unyielding in a dynamic environment and can meet the needs of creative problem solving. Self-efficient employees are more confident in their innovative ideas and are more willing to propose novel ideas in the workplace. While self-efficiency means that employees have the power to do innovative things, high levels of hope indicate that employees can do challenging work in different ways (Luthans et al., 2007). In order to obtain leadership support 
for their innovative ideas and behaviors, employees with high level of hope develop practical solutions based on the leader's hobby, and exhibit determination to overcome risks and challenges brought about by innovation failures. Optimistic individuals can are more likely to control their own destiny and face difficulties as well as failures more calmly. They often have positive expectations of themselves, and thus, are more easily to achieve innovative behavior (Sweetman et al., 2011). Based on the above arguments, we hypothesize that:

H2: Humorous leadership behavior is positively related to EPC.

H3: EPC is positively related to employee creativity.

H4: EPC mediates the relationship between humorous leadership and employee workplace creativity.

\section{The Moderating Role of Supervisor- Subordinate Dyadic Tenure}

While overall, we expect humorous leadership to positively influence employee EPC, there is some evidence that employees differ in the extent of EPC, even in the same context of humorous leadership. To assess this prospect, we draw on Emotional Event Theory (Weiss and Cropanzano, 1996), according to which, the mental state of the leader can be perceived by employees as an environmental impact, which in turn affects the attitudes and behaviors of employees. As managers of the workplace, leaders are responsible for leading employees to complete required tasks. Their mental state and leadership behavior is an important working background against which the employees carry out their daily work; thus, the mental state and leadership of a leader have important influence on the work attitudes and behaviors of employees (Podsakoff et al., 1990; Niehoff and Moorman, 1993).

As mentioned earlier, the supervisor-subordinate dyadic tenure is defined as the duration of time that an employee has worked together with his direct leader. Individuals can achieve a sense of belonging and self-realization through communication and interaction, thus increasing EPC (Quinn and Dutton, 2005). According to Emotional Event Theory, the behavior and performance of employees are the results of the comprehensive influence of the surrounding environment; the behavior and mental state of the leader is a very important factor in the surrounding environment of the employees. The longer of the supervisor-subordinate dyadic tenure, the greater positive interactions and emotional exchanges between the leader and employees are. Further, with greater supervisorsubordinate dyadic tenure, the leader will have more trust and support in their employees (Gkorezis et al., 2011); in turn, the employees will appreciate this and engage in more positive organizational behaviors, such as working harder, taking on more work commitments, and engaging in innovative work methods. All of the organizational behavior mentioned above can contribute to a gaining EPC of employees.

Robert et al. (2016) found that only when an employee works with a leader for a long duration of time will they establish a relationship with high quality exchanges. The longer an employee works with his direct leader, the more they can get to know each other, including each other's behavioral habits, work style, and even hobbies. This will eliminate and avoid misunderstandings caused by insufficient or inappropriate communication. Further, frequent interactions between the leader and employees can help the employees gain psychological power from the guidance of their leader. EPC, which can be increased after training and intervention, is one such important kind of positive psychological power. In short, supervisor-subordinate dyadic tenure provides a valuable time basis and support for positive communication between leaders and employees; that is, the supervisor-subordinate dyadic tenure is longer, the positive relationship between humorous leadership and EPC is stronger. On the contrary, the supervisor-subordinate dyadic tenure is shorter, the positive association between humorous leadership and EPC is weaker. Accordingly, we propose that:

H5: Supervisor-subordinate dyadic tenure moderates the relationship between humorous leadership and EPC.

Based on the discussion above, combined with $\mathrm{H} 4$ and $\mathrm{H} 5$, we further infer that the mediating role of EPC on the relationship between leader's sense of humor and employee creativity can be strengthened in employees who have a longer supervisorsubordinate dyadic tenure. In other words, the mediating role of EPC is moderated by supervisor-subordinate dyadic tenure; thus, we propose a moderated mediation model. Our specific proposition is as follows: supervisor-subordinate dyadic tenure positively moderates the mediating role of EPC on the relationship between humorous leadership and employee creativity. Specifically, when employees and leaders work together for a longer duration of time, the mediating role of EPC is relatively strong; however, when employees and leaders work together for only a short duration of time, the mediating role is relatively weak.

\section{The Moderating Role of Work Autonomy}

Although there are conceptual and empirical reasons to expect that an employee with high EPC will be more creative in the workplace, EPC, by definition, leaves an employee with considerable scope. As mentioned above, creative behavior in the workplace is not clearly listed as a job responsibility, and employees may even bear some risks and losses while being creative; thus, employees face external pressure when they engage in creative behavior. According to Resource Conservation Theory (Hobfoll, 1989), when individuals feel pressure, they will actively seek resources to alleviate the psychological disorder caused by stress; ways in which they may seek such resources include obtaining control and autonomy over their work. Work autonomy, as a key indicator of job characteristics, refers to the degree to which employees can independently control and decide on their working methods, work arrangements, and work standards (Breaugh, 1989). Llopis and Foss (2016) argued that employees with more job autonomy have greater freedom to decide which tasks to perform, how the work will be done and how work contingencies are to be handled. 
Employees with a high degree of autonomy in their work can decide their own work style and schedule; this can intrinsically motivate employees and meet their need for a sense of belonging. When work autonomy is improved, employees have clearer work responsibilities and obligations. All of these factors can lead to workplace creativity. Further, work autonomy can improve the internal perceptions of employees by improving their mental state and work performance (Hackman and Oldham, 1976); work autonomy may also play a role in regulating the relationship between individual emotions and behaviors (Bizzi and Soda, 2011; Wang et al., 2018). Employees with a high degree of work autonomy can participate in the decision-making process; they also have access to job-related information to the fullest extent, and are therefore less affected by contextual factors. This can accelerate the process of transformation from EPC to workplace creativity. Accordingly, we propose that:

H6: Work autonomy moderates the relationship between EPC and workplace creativity.

Based on the discussion above, combined with hypothesis $\mathrm{H} 4$ and $\mathrm{H} 6$, we further infer that the mediating role of psychological capital between humorous leadership and employee creativity is influenced by work autonomy. In other words, the mediating role of psychological capital is moderated by work autonomy. Therefore, we propose the following assumption:

Work autonomy positively moderates the mediating role of psychological capital between humorous leadership and employee creativity. Specifically, when employees have more autonomy in workplace, the mediating role of psychological capital is relatively strong; otherwise, the mediating role is relatively weak.

\section{MATERIALS AND METHODS}

\section{Research Setting and Participants}

This study was conducted in a major information technology (IT) company headquartered in the People's Republic of China (PRC). Participants were professional-level employees whose work required substantial creativity in order to be effective. The direct supervisor of each participating employee was also recruited for this study. We used a pairing survey to collect data from the two sources in order to reduce common method biases. The entire survey was translated from English into Chinese and then back-translated into English by two independent bilingual individuals to ensure equivalency of meaning. Separate questionnaires were designed for direct leaders and employees. The employee questionnaire (questionnaire A) collected data about the employee's evaluation of his direct leader's sense of humor, as well as EPC, work autonomy, and personal information related to the employee. The direct leader questionnaire (questionnaire B) contained an evaluation of employee creativity and collected information related to the team and the leaders themselves.

Before commencing the survey, we contacted the company's human resources (HR) department and got a list of 150 teams of this company. Then, we coded all the questionnaires and matched each leader questionnaire (questionnaire B) with the employee questionnaire (questionnaire $\mathrm{A}$ ). With the name list of the employees in the 150 teams above, we used a simple random sampling method to choose 600 employees to participate in our survey. We distributed a total of 600 employee questionnaires (questionnaire A), and received 423 valid ones, yielding a response rate of $70.5 \%$. Then, we distributed questionnaires (questionnaire B) to the corresponding supervisors of the 423 employees who responded and obtained 355 valid supervisor responses at last. Through sorting out of these questionnaires, we found the 355 employees in our survey were from 83 teams. So, we got 355 pairs of valid samples in our survey in total.

At last, we obtained a total of 355 pairs of leader-member questionnaires, including 83 leaders and 355 employees. Each of these 355 employees was evaluated by his direct leader. Similarly, all the leaders were evaluated by their employees separately. The majority of the participating employees were between 20 and 25 years of age. The employees in this age group accounted for $75.2 \%$ of the total number of participants. The average age of the leaders was 27-29 years of age. Among the employees, there were 197 males, accounting for 55\% of the total number of employees. Male leaders accounted for the majority of the leaders; 83 leaders participated in the survey, 51 of which were males, accounting for $61.4 \%$ of the total number of leaders.

\section{Measures}

\section{Leader's Sense of Humor}

We measured leader sense of humor with a 7-item scale developed by Thorson and Powell (1993). The participants responded using a 5-point scale ranging from $1=$ "strongly disagree" to 5 = "strongly agree." Sample item: "My leader uses humor to entertain coworkers." Cronbach's $\alpha$ was 0.92 .

\section{Employees' Psychological Capital}

EPC was measured with a 24-item scale developed and validated by Luthans et al. (2007). The scale has four sub-scales, namely, hope, resiliency, optimism, and self-efficacy; each scale is measured with six items. Items were measured on a 5-point Likert scale ( $1=$ "strongly disagree" to $5=$ "strongly agree"). Sample items include "I feel confident analyzing a long-term problem to find a solution" (self-efficacy); "I always look on the bright side of things regarding my job" (optimism); "If I should find myself in a jam at work, I could think of many ways to get out of it" (hope); and "I usually take stressful things at work in stride" (resiliency). Cronbach's $\alpha$ was 0.97 .

\section{Work Autonomy}

A 7-item scale adapted by Kirmeyer and Shirom (1986), with minor modification, was used to assess perceived work autonomy. The scale asked participants to indicate the extent to which they agreed with the statement about the freedom they feel regarding to their work, such as when they work, with whom they work, how they finish their work, and so on. Respondents rated their perceived extent of freedom on a 5 -point Likert-type scale ranging from 1 (strongly disagree) 
to 5 (strongly agree). Sample item: "To what extent do you feel you have latitude to decide when to take breaks". Cronbach's $\alpha$ was 0.92 .

\section{Employee Creativity}

Employee creativity was measured with a 13-item scale developed by Zhou and George (2003). Leaders responded on a 5-point scale ranging from 'not at all characteristic' to "very characteristic". Sample item: "He (the employee) is a good source of creative ideas". Cronbach's $\alpha$ was 0.94 .

\section{Supervisor-Subordinate Dyadic Tenure}

Supervisor-subordinate dyadic tenure was measured as the duration of time, the employee had worked with his direct leader.

\section{Control Variables}

We controlled for three demographic variables in our analyses as previous research has found these to be correlated with employee creativity (e.g., Zhou and George, 2003). Age was measured in years. Gender was measured as a dichotomous variable coded as 0 for male and 1 for female. Education was measured as the number of years of post-highschool education.

\section{Measures Validation of Measures}

As reported above, the Cronbach's alphas for all multi-item scales were greater than 0.92 , indicating good reliability. Next, convergent and discriminant validity were evaluated to examine the measurement model. The factor loadings $\lambda$ of all multi-item constructs were higher than 0.60 , the average variance extracted (AVE) for each variable was greater than 0.50 , and the composite reliabilities (CR) were greater than 0.8 , indicating that each measurement construct had great convergence validity (Fornell and Larcker, 1981). In addition, as shown in Table 1, the square root of AVE of each variable on the diagonal was greater than the correlation coefficient of the variables presented in the same row or the same column. Therefore, the variable construction of the four multi-index measurements had good discriminant validity (Fornell and Larcker, 1981).

\section{Analysis}

To test our hypothesized moderated mediation model, we used the SPSS macro PROCESS (version 3.2) developed by Hayes et al. (2017). This allowed us to conduct bootstrapping examinations for moderation and moderated mediation in order to calculate the indirect impact of humorous leadership on employee creativity via EPC, at different levels of supervisorsubordinate dyadic tenure and work autonomy. Before using the SPSS macro PROCESS, all measures in the interaction terms were mean-centered (Aiken et al., 1991).

\section{RESULTS}

The means, standard deviations, and correlations for each study variable are shown in Table 1. All the correlation results were in the expected direction.

Results presented in Table 2 show that, after controlling for the impact of demographic variables, humorous leadership was positively related to employee creativity $(\beta=0.28, p<0.001)$ and EPC $(\beta=0.32, p<0.001)$, and EPC was also positively related to employee creativity $(\beta=0.33, p<0.001)$. These findings are in line with $\mathrm{H} 1, \mathrm{H} 2$, and $\mathrm{H} 3$.

Table 2 shows the results of our H4 mediation hypothesis. It can be seen that when we included both humorous leadership and EPC as independent variables and employee creativity as

TABLE 2 | The mediation role of EPC.

\begin{tabular}{|c|c|c|c|c|c|c|}
\hline \multirow[t]{2}{*}{ Variables } & \multicolumn{2}{|c|}{ EPC } & \multicolumn{4}{|c|}{ Employee creativity } \\
\hline & Model 1 & Model 2 & Model 3 & Model 4 & Model 5 & Model 6 \\
\hline Age & $0.13^{*}$ & $0.14^{\star *}$ & $0.14^{\star}$ & $0.14^{\star \star}$ & 0.09 & $0.11^{*}$ \\
\hline Gender & $0.13^{\star}$ & 0.08 & 0.09 & 0.04 & 0.04 & 0.02 \\
\hline ED & $0.14^{\star *}$ & $0.14^{\star \star}$ & $0.12^{\star}$ & $0.12^{\star}$ & 0.08 & 0.09 \\
\hline $\mathrm{HL}$ & - & $0.32^{\star \star \star}$ & - & $0.28^{\star \star \star}$ & - & $0.20^{\star \star \star}$ \\
\hline EPC & - & - & - & - & $0.33^{\star \star \star}$ & $0.27^{\star \star \star}$ \\
\hline Adjusted $R^{2}$ & 0.04 & 0.14 & 0.03 & 0.11 & 0.13 & 0.16 \\
\hline$F$ & $6.40^{\star \star \star}$ & $15.71^{\star \star \star}$ & $4.64^{\star \star}$ & $11.52^{\star \star \star}$ & $14.48^{\star \star \star}$ & $14.92^{\star \star \star}$ \\
\hline
\end{tabular}

${ }^{*} p<0.05 ;{ }^{* *} p<0.01 ;{ }^{* * *} p<0.001$. EC, employee creativity; $E D$, education; EPC, employees' psychological capital; HL, humorous leadership.

TABLE 1 | Descriptive statistics, correlations, and reliabilities $(N=355)$.

\begin{tabular}{|c|c|c|c|c|c|c|c|c|c|}
\hline & & 1 & 2 & 3 & 4 & 5 & 6 & 7 & 8 \\
\hline 1 & Age & NA & & & & & & & \\
\hline 2 & Gender & $0.18^{\star \star}$ & NA & & & & & & \\
\hline 3 & ED & $0.19^{\star \star}$ & 0.05 & NA & & & & & \\
\hline 4 & $\mathrm{HL}$ & 0.01 & $0.15^{\star \star}$ & 0.03 & 0.79 & & & & \\
\hline 5 & SDT & $0.29^{\star \star}$ & 0.07 & 0.05 & 0.07 & NA & & & \\
\hline 6 & EPC & $0.13^{*}$ & $0.15^{\star \star}$ & $0.14^{\star \star}$ & $0.33^{\star \star \star}$ & 0.09 & 0.76 & & \\
\hline 7 & WA & $0.12^{*}$ & 0.10 & $0.11^{\star}$ & $0.20^{\star \star \star}$ & 0.07 & $0.57^{\star \star \star}$ & 0.80 & \\
\hline \multirow[t]{3}{*}{8} & EC & $0.13^{\star}$ & 0.10 & 0.10 & $0.29^{\star \star \star}$ & $0.20^{\star \star \star}$ & $0.36^{\star \star \star}$ & $0.30^{\star \star \star}$ & 0.75 \\
\hline & Mean & 22.12 & 0.44 & 1.80 & 4.07 & 1.27 & 3.97 & 3.30 & 3.28 \\
\hline & $\mathrm{SD}$ & 1.94 & 0.50 & 1.58 & 0.75 & 0.65 & 0.69 & 0.92 & 0.70 \\
\hline
\end{tabular}

The square roots of AVE for the four multi-index constructs are given in parentheses on the diagonal. * $p<0.05 ;{ }^{* *} p<0.01$; ${ }^{* * *} p<0.001$. EC, employee creativity; ED, education; EPC, Employees' psychological capital; HL, humorous leadership; NA, not available; SDT, supervisor-subordinate dyadic tenure; WA, work autonomy. 
the dependent variable, EPC had a positive impact on employee creativity $(\beta=0.27, p<0.001)$ while humorous leadership continued to have a significant impact on employee creativity, although the predictive effect was significantly attenuated $(\beta=0.20$, $p<0.001)$. This indicates that there is a partial mediation effect. Finally, the bias-corrected percentile bootstrap method indicated that the indirect impact of humorous leadership on employee creativity through EPC was significant, effect $=0.18$, with a $95 \%$ CI of [0.0002, 0.0889]. Thus, H4 was supported.

Table 3 shows the results of our H5 and H6 moderation hypotheses. As can be seen below, the effect of the interaction between humorous leadership and supervisor-subordinate dyadic tenure on EPC was not significant; thus, H5 was not supported. On the other hand, the interaction between EPC and work autonomy was found to positively predict employee creativity ( $\beta=0.14, p<0.05)$, even when controlling for demographic variables. Figure 2 shows that when the level of work autonomy

TABLE 3 | Moderation effect of the model.

\begin{tabular}{|c|c|c|c|c|c|c|}
\hline \multirow[t]{2}{*}{ Variables } & \multicolumn{6}{|c|}{ Moderation effect } \\
\hline & Model 1 & Model 2 & Model 3 & Model 4 & Model 5 & Model 6 \\
\hline Age & $0.13^{\star}$ & 0.11 & 0.08 & 0.08 & 0.04 & 0.034 \\
\hline Gender & $0.13^{\star}$ & $0.13^{*}$ & $0.13^{\star}$ & $0.13^{*}$ & 0.09 & $0.085^{\star \star}$ \\
\hline ED & $0.14^{\star \star}$ & $0.14^{\star \star}$ & $0.14^{\star \star}$ & $0.12^{*}$ & 0.07 & 0.063 \\
\hline $\mathrm{HL}$ & & $0.32^{\star \star \star}$ & $0.33^{\star \star \star}$ & & & \\
\hline SDT & & 0.04 & 0.02 & & & \\
\hline EPC & & & & & $0.26^{\star \star \star}$ & $0.33^{\star \star \star}$ \\
\hline WA & & & & & $0.14^{*}$ & $0.13^{\star}$ \\
\hline $\mathrm{HL}^{\star} \mathrm{SDT}$ & & & 0.053 & & & \\
\hline$P C^{*} W A$ & & & & & & $0.14^{*}$ \\
\hline Adjusted $R^{2}$ & 0.05 & 0.141 & 0.141 & 0.03 & 0.142 & 0.15 \\
\hline$F$ & $6.39^{\star \star \star}$ & $12.65^{\star \star \star}$ & $10.70^{\star \star \star}$ & $4.64^{\star \star \star}$ & $12.72^{\star \star \star}$ & $11.74^{\star \star \star}$ \\
\hline
\end{tabular}

is high, the employee's creativity increases more, and when the level of autonomy is low, the increase is small. It can be intuitively seen that work autonomy strengthens the positive effect of psychological capital on employee creativity. Thus, overall, H6 was supported.

Finally, PROCESS macro in combination with the Bootstrap method proposed by Hayes et al. (2017) were used to further examine the conditional indirect effect of humorous leadership on employee creativity through EPC, at two levels of employee work autonomy (+1 SD above the mean and $-1 \mathrm{SD}$ below the mean). In Table 4, results showed that the conditional indirect effect of humorous leadership on employee creativity via EPC was 0.11 with a $95 \%$ CI of $[0.050,0.189]$ when the level of work autonomy was high, versus 0.05 with a $95 \% \mathrm{CI}$ of $[0.017,0.101]$ when the level of work autonomy was low. Additionally, the moderated mediation index was also significant 0.03 , with a $95 \%$ CI of $[0.0058,0.0601]$.

\section{DISCUSSION}

In this paper, we built and tested a conceptual model that uniquely combines humorous leadership theory with creativity theory. Although a number of studies have investigated relationship between leadership style and creativity (Zhou and George, 2003; Amabile et al., 2004), humorous leadership has been surprisingly absent from consideration. Yet, as we have argued and uniquely modeled, there are strong theoretical reasons to expect humorous leadership to be well positioned to influence fundamentals underlying employee creativity, a contention that we have empirically supported here. Our results support suggestions of creativity scholars that leadership approaches may be an effective means for encouraging employee creativity.

Our research makes a number of important theoretical contributions to the literature on humor and creativity. Using the theory of emotional events, this paper introduces EPC as a mediator
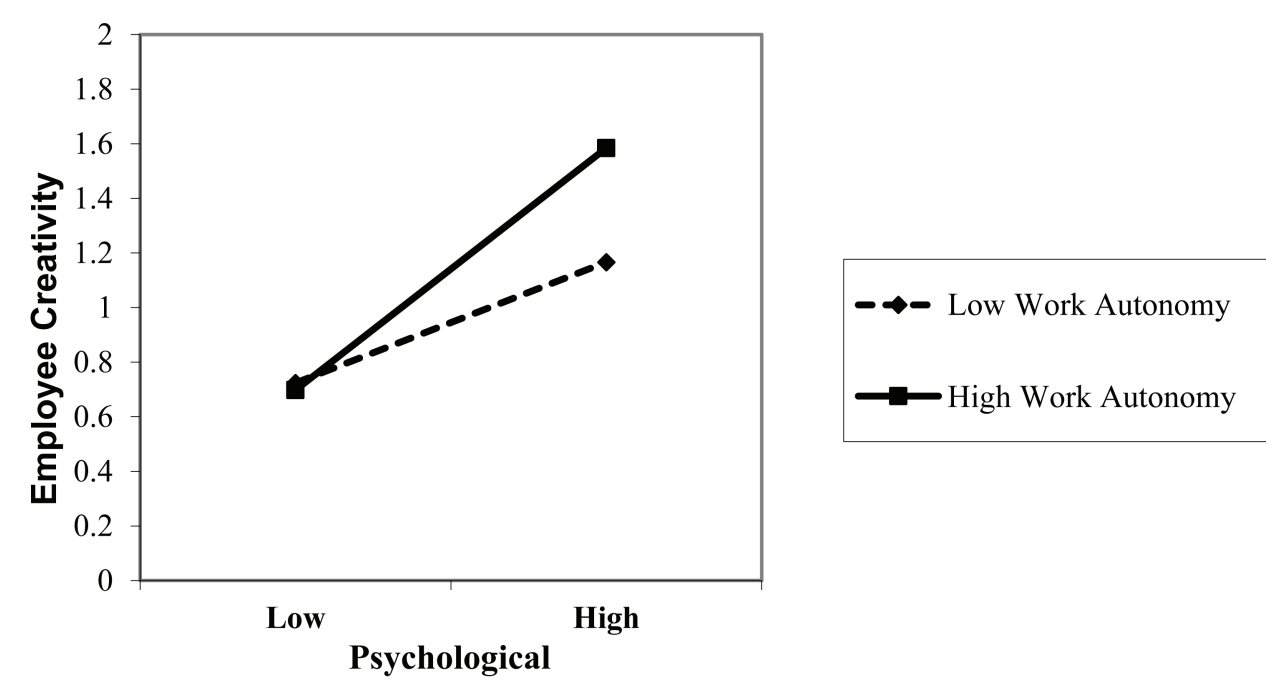

FIGURE 2 | Moderation effect of work autonomy. 
TABLE 4 | Bootstrap test results of moderated mediating effect.

\begin{tabular}{|c|c|c|c|c|c|c|c|c|c|}
\hline \multirow[b]{2}{*}{ Dependent variable } & \multicolumn{5}{|c|}{ Indirect effect } & \multicolumn{4}{|c|}{ Moderated mediating effect } \\
\hline & Work autonomy & Effect & SE & 95\% LLCI & $95 \%$ ULCI & INDEX & SE & 95\% LLCI & $95 \%$ ULCI \\
\hline Employee & Low & 0.05 & 0.02 & 0.017 & 0.101 & \multirow{2}{*}{0.03} & \multirow{2}{*}{0.014} & \multirow{2}{*}{0.0058} & \multirow{2}{*}{0.0601} \\
\hline Creativity & High & 0.11 & 0.03 & 0.050 & 0.189 & & & & \\
\hline
\end{tabular}

$N=355$, confidence interval $95 \%$.

variable, linking the behavior of the leaders with employee psychology and employee behavior. At the same time, we also introduce supervisor-subordinate dyadic tenure and employee work autonomy as two situational factors to study their moderating effects on the model. Based on the empirical findings, it is confirmed that humorous leadership has a significant positive impact on employee creativity, and EPC plays a partial mediation role. At the same time, employee work autonomy positively moderates the relationship between EPC and employee creativity. When employees have a high level of work autonomy, EPC has a greater impact on employee creativity. The findings suggest that this is a moderated mediation model, which indicates that employee work autonomy not only moderates the positive relationship between EPC and employee creativity, but also moderates the mediation effect of EPC on the relationship between humorous leadership and employee creativity. When employees have a high level of work autonomy, EPC has a stronger mediating effect on the link between humorous leadership and employee creativity.

Our theoretical model also has some practical implications for companies especially for managers. Firstly, in encouraging employee creativity, leadership does matter. Specifically, our results suggest that humorous leadership has the capacity to positively influence employee EPC, and it is an important role in influencing employee creativity. Thus, in order to improve employee creativity, one effective way is to enhance the psychological state of the employees, including level of self-efficacy, optimism, hope, and resilience. For managers, it is desirable and even necessary to become humorous in the workplace. Further, work autonomy acts as a situational factor, influencing the link between employee EPC and employee creativity. Managers need to make a conscious effort to effectively improve the work autonomy of employees. With high level of autonomy at work, employees can freely determine issues at work such as when to rest, who they would like to work with, etc.

Till now, few scholars have combined humorous leadership styles with the psychological capital of employees to explore employee creativity like us. It is easy to see that leadership style is an important factor for the work attitude and behavior of employees (especially creativity in the workplace), and the psychological state of employees is the direct influence of behavior. What is more, the theory of Emotional Events also proves this path from which employees accrue creativity with the help of humorous leader. In practice, the results of our research are also meaningful. By following the advice given in the article, we can expect companies effectively improve employees' creativity in the workplace.

Like any study, this study is not without limitations. Firstly, self-report methods were used to collect data from employees, raising the possibility of same-source bias. Since the measured constructs (EPC, supervisor-subordinate dyadic tenure, and work autonomy) address the individual's internal states, we would argue that it is logical to collect the data from the participants themselves. A mitigating factor is that the ratings of employee creativity were collected from each employee's direct leader, and leader's sense of humor was evaluated by their employees.

The second limitation is that the sample was obtained from a single IT company in China; this limits the diversity of the sample. Of course, conducting this study in one organization did allow for control of potential organization-level confounding variables. However, this also limits the universality of our model. Future research should sample from a wide range of sources, including from different industries and different regions.

Third, supervisor-subordinate dyadic tenure was not found to act as a moderator, as was hypothesized. This may because leader's sense of humor is relatively easy to detect at first glance. Thus, enhancement of EPC may occur quickly in the dyadic relationship. In that case, the time employee work with their direct leader may be of little significance. There are other situational innovation atmosphere, etc. Further, creativity is contingent on a variety of individual differences, such as family background, creative self-efficacy, personality, knowledge, and skills. Future research should take these related variables into consideration and apply them to our model.

\section{DATA AVAILABILITY}

All datasets generated for this study are included in the manuscript and/or the supplementary files.

\section{ETHICS STATEMENT}

This study was conducted in accordance with the ethical guidelines of the Institutional Review Board of Zhejiang University of Technology (ZJUT) in China, with written informed consent from all subjects. All the employees participated in the survey voluntarily. The protocol was approved by the Institutional Review Board of ZJUT and the Secretariat of Academic Committee of ZJUT, with the permit number 2018001.

\section{AUTHOR CONTRIBUTIONS}

ZL provided the resource, designed the research, and wrote the first draft of the manuscript. LD collected the data, 
performed the statistical analysis, and wrote the first draft of the manuscript. TC helped to develop the hypotheses and revised the manuscript. MR revised and copyedited the manuscript.

\section{REFERENCES}

Adriaenssens, J., De Gucht, V., and Maes, S. (2015). Causes and consequences of occupational stress in emergency nurses, a longitudinal study. J. Nurs. Manag. 23, 346-358. doi: 10.1111/jonm.12138

Aiken, L. S., West, S. G., and Reno, R. R. (1991). Multiple regression: Testing and interpreting interactions. Thousand Oaks, CA: Sage.

Al Obthani, H. S., Omar, R. B., and Bakri, N. B. (2013). The origins of workplace humor and its definition. Am. Acad. Scholarly Res. J. 5, 67-73.

Amabile, T. M. (1988). A model of creativity and innovation in organizations. Res. Organ. Behav. 10, 123-167.

Amabile, T. M., Schatzel, E. A., Moneta, G. B., and Kramer, S. J. (2004). Leader behaviors and the work environment for creativity: perceived leader support. Leader. Q. 15, 5-32. doi: 10.1016/j.leaqua.2003.12.003

Avey, J. B., Luthans, F., and Jensen, S. M. (2009). Psychological capital: a positive resource for combating employee stress and turnover. Hum. Resour. Manag. 48, 677-693. doi: 10.1002/hrm.20294

Avolio, B. J., Howell, J. M., and Sosik, J. J. (1999). A funny thing happened on the way to the bottom line: humor as a moderator of leadership style effects. Acad. Manag. J. 42, 219-227.

Avolio, B. J., and Walumbwa, F. O. (2006). Authentic leadership: moving HR leaders to a higher level. Res. Pers. Human. Res. Man. 25, 273-304. doi: 10.1016/S0742-7301(06)25007-2

Bizi, S., Keinan, G., and Beit-Hallahmi, B. (1988). Humor and coping with stress: a test under real-life conditions. Pers. Individ. Dif. 9, 951-956. doi: 10.1016/0191-8869(88)90128-6

Bizzi, L., and Soda, G. (2011). The paradox of authentic selves and chameleons: self-monitoring, perceived job autonomy and contextual performance. $\mathrm{Br}$. J. Manag. 22, 324-339. doi: 10.1111/j.1467-8551.2011.00747.x

Breaugh, J. A. (1989). The work autonomy scales: additional validity evidence. Hum. Relations. 42, 1033-1056.

Carmeli, A., Reiter-Palmon, R., and Ziv, E. (2010). Inclusive leadership and employee involvement in creative tasks in the workplace: the mediating role of psychological safety. Creativity Res. J. 22, 250-260. doi: 10.1080/10400419.2010.504654

Chan, S. C. (2014). Paternalistic leadership and employee voice: does information sharing matter? Hum. Relations 67, 667-693. doi: 10.1177/ 0018726713503022

Chang, J. H., Chen, H. C., Hsu, C. C., Chan, Y. C., and Chang, Y. L. (2015). Flexible humor styles and the creative mind: using a typological approach to investigate the relationship between humor styles and creativity. Psychol. Aesthet. Creat. Arts 9, 306-312. doi: 10.1037/a0039527

Chen and Chen (2011). Humorous leader. Beijing: Tsinghua University Press.

Chin, T., and Liu, R. H. (2015). Understanding labor conflicts in Chinese manufacturing: a Yin-Yang harmony perspective. Int. J. Confl. Manag. 26, 288-315. doi: 10.1108/IJCMA-09-2014-0074

Cho, J., and Dansereau, F. (2010). Are transformational leaders fair? A multilevel study of transformational leadership, justice perceptions, and organizational citizenship behaviors. Leader. Q. 21, 409-421. doi: 10.1016/j. leaqua.2010.03.006

Cooper, C. D. (2005). Just joking around? Employee humor expression as an ingratiatory behavior. Acad. Manag. Rev. 30, 765-776. doi: 10.5465/ amr.2005.18378877

Cooper, C. (2008). Elucidating the bonds of workplace humor: a relational process model. Hum. Relations. 61, 1087-1115. doi: 10.1177/0018726708094861

Delaney, J. T., and Huselid, M. A. (1996). The impact of human resource management practices on perceptions of organizational performance. Acad. Manag. J. 39, 949-969.

Du, Y., Xu, L., Xi, Y. M., and Ge, J. (2019). Chinese leader-follower flexible interactions at varying leader distances: an exploration of the effects of

\section{FUNDING}

This work was supported by the Philosophy and Social Science Planning Project of Zhejiang Province, China (19NDJC023Z).

followers in school cases. Chin. Manag. Stu. 13, 191-213. doi: 10.1108/ CMS-03-2018-0461

Fornell, C., and Larcker, D. F. (1981). Structural equation models with unobservable variables and measurement error: algebra and statistics. J. Mar. Res. 18, 382-388.

Ghosh, K. (2015). Developing organizational creativity and innovation: toward a model of self-leadership, employee creativity, creativity climate and workplace innovative orientation. Manag. Res. Rev. 38, 1126-1148. doi: 10.1108/ MRR-01-2014-0017

Gkorezis, P., Hatzithomas, L., and Petridou, E. (2011). The impact of leader's humor on employees' psychological empowerment: the moderating role of tenure. J. Manag. Issues 23, 83-95.

Gong, Y., Huang, J. C., and Farh, J. L. (2009). Employee learning orientation, transformational leadership, and employee creativity: the mediating role of employee creative self-efficacy. Acad. Manag. J. 52, 765-778. doi: 10.5465/ amj.2009.43670890

Goswami, A., Nair, P., Beehr, T., and Grossenbacher, M. (2016). The relationship of leaders' humor and employees' work engagement mediated by positive emotions: moderating effect of leaders' transformational leadership style. Leadersh. Org. Develop. J. 37, 1083-1099. doi: 10.1108/LODJ-01-2015-0001

Gupta, V., and Singh, S. (2014). Psychological capital as a mediator of the relationship between leadership and creative performance behaviors: empirical evidence from the Indian R\&D sector. Int. J. Hum. Resour. Manag. 25, 1373-1394. doi: 10.1080/09585192.2013.870311

Gupta, V., Singh, S., No, R., and Block, C. (2011). "Development of a causal framework linking leadership to employee creativity" in Proceedings of the 2011 Meeting of Southern Management Association, Savanah, US 13-18.

Hackman, J. R., and Oldham, G. R. (1976). Motivation through the design of work: test of a theory. Organ. Behav. Hum. Perform. 16, 250-279. doi: 10.1016/0030-5073(76)90016-7

Hayes, A. F., Montoya, A. K., and Rockwood, N. J. (2017). The analysis of mechanisms and their contingencies: process versus structural equation modeling. Australas. Mark. J. 25, 76-81. doi: 10.1016/j.ausmj.2017.02.001

Hobfoll, S. E. (1989). Conservation of resources: a new attempt at conceptualizing stress. Am. Psychol. 44, 513-524. doi: 10.1037/0003-066X.44.3.513

Holmes, J. (2007). Making humour work: creativity on the job. Appl. Linguis. 28, 518-537. doi: 10.1093/applin/amm048

Hommel, B., Colzato, L. S., Fischer, R., and Christoffels, I. K. (2011). Bilingualism and creativity: benefits in convergent thinking come with losses in divergent thinking. Front. Psychol. 2, 2-5. doi: 10.3389/fpsyg.2011.00273

Iqbal, N., Anwar, S., and Haider, N. (2015). Effect of leadership style on employee performance. Arab. J. Bus. Manag. Rev. 5, 1-6. doi: 10.4172/2223-5833.1000146

Kim, T. Y., Lee, D. R., and Wong, N. Y. S. (2016). Supervisor humor and employee outcomes: the role of social distance and affective trust in supervisor. J. Bus. Psychol. 31, 125-139. doi: 10.1007/s10869-015-9406-9

Kirmeyer, S. L., and Shirom, A. (1986). Perceived job autonomy in the manufacturing sector: effects of unions, gender, and substantive complexity. Acad. Manag. J. 29, 832-840.

Lang, J. C., and Lee, C. H. (2010). Workplace humor and organizational creativity. Int. J. Hum. Resour. Manag. 21, 46-60. doi: 10.1080/09585190903466855

Lebedeva, N., Schwartz, S. H., Van De Vijver, F. J., Plucker, J., and Bushina, E. (2018). Domains of everyday creativity and personal values. Front. Psychol. 9, 1-52. doi: 10.3389/fpsyg.2018.02681

Llopis, O., and Foss, N. J. (2016). Understanding the climate-knowledge sharing relation: the moderating roles of intrinsic motivation and job autonomy. Eur. Manag. J. 34, 135-144. doi: 10.1016/j.emj.2015.11.009

Luthans, F., Youssef, C. M., and Avolio, B. J. (2007). Psychological capital: Developing the human competitive edge. New York, NY: Oxford University Press.

Martin, R. A. (2001). Humor, laughter, and physical health: methodological issues and research findings. Psychol. Bull. 127, 504-519. doi: 10.1037/0033-2909.127.4.504 
Martin, R. A., Puhlik-Doris, P., Larsen, G., Gray, J., and Weir, K. (2003). Individual differences in uses of humor and their relation to psychological well-being: development of the humor styles questionnaire. J. Res. Pers. 37, 48-75. doi: 10.1016/S0092-6566(02)00534-2

McGraw, A. P., and Warren, C. (2010). Benign violations: making immoral behavior funny. Psychol. Sci. 21, 1141-1149. doi: 10.1177/0956797610376073

Musinguzi, C., Namale, L., Rutebemberwa, E., Dahal, A., Nahiryantege, P., and Kekitiinwa, A. (2018). The relationship between leadership style and health worker motivation, job satisfaction and teamwork in Uganda. Healthc. Leadersh. 10, 21-32. doi: 10.2147/JHL.S147885

Niehoff, B. P., and Moorman, R. H. (1993). Justice as a mediator of the relationship between methods of monitoring and organizational citizenship behavior. Acad. Manag. J. 36, 527-556.

Nonaka, I., and Zhu, Z. (2012). Pragmatic strategy: Eastern wisdom, global success. Cambridge, MA: Cambridge University Press.

Oldham, G. R., and Cummings, A. (1996). Employee creativity: personal and contextual factors at work. Acad. Manag. J. 39, 607-634.

Podsakoff, P. M., MacKenzie, S. B., Moorman, R. H., and Fetter, R. (1990). Transformational leader behaviors and their effects on followers' trust in leader, satisfaction, and organizational citizenship behaviors. Leader. Q. 1, 107-142. doi: 10.1016/1048-9843(90)90009-7

Pundt, A. (2015). The relationship between humorous leadership and innovative behavior. J. Manag. Psychol. 30, 878-893. doi: 10.1108/JMP-03-2013-0082

Quinn, R. W., and Dutton, J. E. (2005). Coordination as energy-in-conversation. Acad. Manag. Rev. 30, 36-57. doi: 10.5465/amr.2005.15281422

Rafiq, M., Weiwei, W., Chin, T., and Nasir, M. (2019). The moderating effect of career stage on the relationship between job embeddedness and innovationrelated behaviour (IRB) evidence from China. World J. Entrep. Manag. Sustain. Dev. 15, 109-122. doi: 10.1108/WJEMSD-04-2018-0045

Rego, A., Sousa, F., Marques, C., and e Cunha, M. P. (2012). Authentic leadership promoting employees' psychological capital and creativity. J. Bus. Res. 65, 429-437. doi: 10.1016/j.jbusres.2011.10.003

Robert, C., Dunne, T. C., and Iun, J. (2016). The impact of leader humor on subordinate job satisfaction: the crucial role of leader-subordinate relationship quality. Group Organ. Manag. 41, 375-406. doi: 10.1177/1059601115598719

Robert, C., and Wilbanks, J. E. (2012). The wheel model of humor: humor events and affect in organizations. Hum. Relat. 65, 1071-1099. doi: $10.1177 / 0018726711433133$

Robinson, S. L., and Bennett, R. J. (1995). A typology of deviant workplace behaviors: a multidimensional scaling study. Acad. Manag. J. 38, 555-572.

Scott, S. G., and Bruce, R. A. (1994). Determinants of innovative behavior: a path model of individual innovation in the workplace. Acad. Manag. J. 37, 580-607.

Shalley, C. E. (1991). Effects of productivity goals, creativity goals, and personal discretion on individual creativity. J. Appl. Psychol. 76, 179-185. doi: 10.1037/0021-9010.76.2.179

Shin, S. J., and Zhou, J. (2003). Transformational leadership, conservation, and creativity: evidence from Korea. Acad. Manag. J. 46, 703-714. doi: 10.5465/30040662

Silla, I., and Gamero, N. (2018). Psychological safety climate and professional drivers' well-being: the mediating role of time pressure. Transp. Res. Part F Traffic Psychol. Behav. 53, 84-92. doi: 10.1016/j.trf.2017.12.002

Sobral, F., and Islam, G. (2015). He who laughs best, leaves last: the influence of humor on the attitudes and behavior of interns. Acad. Manag. Learn. Educ. 14, 500-518. doi: 10.5465/amle.2013.0368

Sweetman, D., Luthans, F., Avey, J. B., and Luthans, B. C. (2011). Relationship between positive psychological capital and creative performance. Can. J. Admin. Sci. 28, 4-13. doi: 10.1002/cjas.175
Thorson, J. A., and Powell, F. C. (1993). Development and validation of a multidimensional sense of humor scale. J. Clin. Psychol. 49, 13-23. doi: 10.1002/1097-4679(199301)49:1<13::AID-JCLP2270490103>3.0.CO;2-S

Tierney, P., and Farmer, S. M. (2011). Creative self-efficacy development and creative performance over time. J. Appl. Psychol. 96, 277-293. doi: 10.1037/ a0020952

Tierney, P., Farmer, S. M., and Graen, G. B. (1999). An examination of leadership and employee creativity: the relevance of traits and relationships. Pers. Psychol. 52, 591-620. doi: 10.1111/j.1744-6570.1999.tb00173.x

Tsai, C. Y., Horng, J. S., Liu, C. H., and Hu, D. C. (2015). Work environment and atmosphere: the role of organizational support in the creativity performance of tourism and hospitality organizations. Int. J. Hosp. Manag. 46, 26-35. doi: 10.1016/j.ijhm.2015.01.009

Veatch, T. C. (1998). A theory of humor. Humor Int. J. Humor Res. 11, 161-216.

Vecchio, R., Justin, J., and Pearce, C. (2009). The influence of leader humor on relationships between leader behavior and follower outcomes. J. Manag. Issues 21, 171-194.

Walumbwa, F. O., Wang, P., Wang, H., Schaubroeck, J., and Avolio, B. J. (2010). Psychological processes linking authentic leadership to follower behaviors. Leader. Q. 21, 901-914. doi: 10.1016/j.leaqua.2010.07.015

Wang, Y., Liu, J., and Yu, Z. (2018). How does humble leadership promote follower creativity? The roles of psychological capital and growth need strength. Lead. Organ. Dev. J. 39, 507-521. doi: 10.1108/LODJ-03-2017-0069

Wang, K., and Wang, Y. (2018). Person-environment fit and employee creativity: the moderating role of multicultural experience. Front. Psychol. 9, 1-11. doi: $10.3389 /$ fpsyg.2018.01980

Weiss, H. M., and Cropanzano, R. (1996). Affective events theory: a theoretical discussion of the structure, causes and consequences of affective experiences at work. Res. Organ. Behav. 18, 1-74.

Wood, R. E., Beckmann, N., and Rossiter, J. R. (2011). Management humor: asset or liability? Org. Psychol. Rev. 1, 316-338. doi: 10.1177/2041386611418393

Yam, K. C., Christian, M. S., Wei, W., Liao, Z., and Nai, J. (2018). The mixed blessing of leader sense of humor: examining costs and benefits. Acad. Manag. J. 61, 348-369. doi: 10.5465/amj.2015.1088

Zhang, X., and Bartol, K. M. (2010). Linking empowering leadership and employee creativity: the influence of psychological empowerment, intrinsic motivation, and creative process engagement. Acad. Manag. J. 53, 107-128. doi: $10.5465 /$ amj.2010.48037118

Zhou, J., and George, J. M. (2003). Awakening employee creativity: the role of leader emotional intelligence. Leader. Q. 14, 545-568. doi: 10.1016/ S1048-9843(03)00051-1

Zubair, A., and Kamal, A. (2015). Work related flow, psychological capital, and creativity among employees of software houses. Psychol. Stud. 60, 321-331. doi: 10.1007/s12646-015-0330-x

Conflict of Interest Statement: The authors declare that the research was conducted in the absence of any commercial or financial relationships that could be construed as a potential conflict of interest.

Copyright (c) 2019 Li, Dai, Chin and Rafiq. This is an open-access article distributed under the terms of the Creative Commons Attribution License (CC $B Y)$. The use, distribution or reproduction in other forums is permitted, provided the original author(s) and the copyright owner(s) are credited and that the original publication in this journal is cited, in accordance with accepted academic practice. No use, distribution or reproduction is permitted which does not comply with these terms. 